\title{
Structure and Performance
}

\section{Ownership Conversions and Nursing Home Performance}

\author{
David C. Grabowski and David G. Stevenson
}

Objective. To examine the effects of ownership conversions on nursing home performance.

Data Source. Online Survey, Certification, and Reporting system data from 1993 to 2004, and the Minimum Data Set (MDS) facility reports from 1998 to 2004.

Study Design. Regression specification incorporating facility fixed effects, with terms to identify trends in the pre- and postconversion periods.

Principal Findings. The annual rate of nursing home conversions almost tripled between 1994 and 2004. Our regression results indicate converting facilities are generally different throughout the pre/postconversion years, suggesting little causal effect of ownership conversions on nursing home performance. Before and after conversion, nursing homes converting from nonprofit to for-profit status generally exhibit deterioration in their performance, while nursing homes converting from for-profit to nonprofit status generally exhibit improvement.

Conclusions. Policy makers have expressed concern regarding the implications of ownership conversions for nursing home performance. Our results imply that regulators and policy makers should not only monitor the outcomes of nursing home conversions, but also the targets of these conversions.

Key Words. Ownership, conversions, nursing homes, quality

Quality has been a long standing policy issue in the nursing home sector with over three decades of research establishing substandard care practices in particular facilities (Institute of Medicine 2001). Given that nearly two-thirds of nursing homes are for-profit owned, there has been an interest among researchers and policy makers in establishing a causal link between ownership status and quality of care. In a comprehensive literature review of 38 studies published over the period 1990-2002, Hillmer et al. (2005) concluded that quality was lower in for-profit nursing homes. However, this previous literature is based almost entirely on cross-sectional comparisons of nonprofit and for-profit nursing homes. 
The last decade has been a period of tremendous change within the nursing home sector, with many of the nation's largest nursing home chains going through periods of considerable expansion and contraction (Stevenson, Grabowski, and Coots 2006). Although the majority of facility transactions occur within ownership type, there were nearly 3,000 conversions across for-profit, nonprofit, and government status over the period 1993-2004, with a large increase in the latter part of the period. These conversions may affect a facility's administrative and nursing staff turnover, access to capital, willingness to accept less profitable patients, and overall quality of care. Previous research has not directly tested whether conversions across ownership form have implications for attributes of nursing home behavior such as quality of care.

A study of ownership conversions is potentially compelling on two levels (Picone, Chou, and Sloan 2002). First, from the perspective of public policy, state and federal policy makers are asked to make decisions exactly on these changes. Several states such as New York have enacted rules to oversee (and potentially limit) for-profit nursing home entry. More recently, in response to a New York Times article describing substantial private equity investment in the nursing home sector and subsequent quality of care concerns, the U.S. Congress announced plans to investigate business practices at facilities owned by private investment groups (Duhigg 2007a, b). Second, from a methodological perspective, by focusing the analysis on changes in ownership status, we can hold other relevant facility characteristics, such as location, constant. Previous research has shown that for-profit hospital performance is attributable, in part, to where the hospital is located (Norton and Staiger 1994). Compared with the cross-sectional approach often employed in the literature, this empirical framework provides a more precise means of identifying the effects of ownership on nursing home performance.

The goal of this paper is to examine nursing home performance following a conversion between for-profit and nonprofit ownership status. Specifically, we explore changes in occupancy, payer mix, staffing ratios, and a range of quality indicators (QIs) following ownership conversions. With a long panel (1993-2004), we are able to implement a differences-in-differences approach to address potential selection biases at the level of the facility. Given that

Address correspondence to David C. Grabowski, Ph.D., Department of Health Care Policy, Harvard Medical School, 180 Longwood Avenue, Boston, MA 02115-5899. E-mail: grabowski@ hcp.med.harvard.edu. David G. Stevenson, Ph.D., is with the Department of Health Care Policy, Harvard Medical School, Boston, MA. 
conversions are usually preceded by financial difficulties (Sloan, Ostermann, and Conover 2003), we examine quality in the periods preceding conversion, and how it evolves in the periods following conversion.

\section{CONCEPTUAL FRAMEWORK}

\section{Background}

The most recent National Nursing Home Survey counted 1.5 million Americans living in approximately 16,100 nursing homes nationwide in 2004 (National Center for Health Statistics 2006). It has been projected that in the next 20 years, 46 percent of Americans who survive to age 65 will use a nursing home at some point in their lives (Spillman and Lubitz 2002). Nursing home expenditures totaled $\$ 115.2$ billion in 2004, which represented 6.1 percent of national health expenditures (Smith et al. 2006). The nursing home market consists of both custodial (long-stay) and postacute (short-stay) residents. Medicaid is the dominant payer of custodial nursing home services, accounting for roughly 50 percent of all nursing home expenditures and 70 percent of all bed days. Medicare covers postacute nursing home care, which accounts for 12 percent of total nursing home expenditures. The remainder of care is financed primarily by private out-of-pocket payments.

For-profit nursing homes, constituting roughly two-thirds of all facilities, may be owned by an individual, partnership, or corporation. Nonprofits make up approximately one-fourth of all facilities. Nonprofits are predominantly church related or a nonprofit corporation. The remaining nursing homes (roughly 7 percent) are government owned. Government-owned facilities may be run by the state, county, city, hospital district, or the federal government.

No standard protocols exist for nursing homes following a conversion or sale. Administrative and care staff would not be expected to change as a matter of course; however, these transitions might occur when facilities are acquired by organizations with managerial approaches different from prior ownership or when facilities are sold for reasons having to do with poor quality (e.g., if a state survey agency compels an ownership change following poor inspection results). Government oversight of conversions varies across state licensure and survey programs. In particular, some states might exercise greater scrutiny over conversions to for-profit status, especially if ownership is based outside the particular state (e.g., New York State does not allow out-of-state for-profit chains to operate facilities in the state). Most—if not all—states must approve sales involving nursing homes, and the Centers for Medicare and Medicaid 
Services is involved if a facility's certification status changes in the course of a transaction. Finally, an inspection by the state survey agency generally occurs concurrently with any change of ownership.

\section{Nursing Home Objectives}

For-profit nursing homes maximize profits by setting output, quality, inputs, and patient mix at levels to achieve this objective. Unlike their for-profit counterparts, nonprofits cannot distribute accounting profits to individual equity holders. In return, nonprofits enjoy several government-conferred advantages, including exemption from corporate income and property taxes and a lower cost of capital through tax-exempt donations. For government nursing homes, the residual claimant is also not explicit.

The Medicaid and Medicare price for nursing home care does not depend on quality of care, but Medicare and Medicaid recipients may still choose nursing homes on the basis of quality. Clearly, certain aspects of quality are observable to patients (and their families) and other aspects are unobservable, even with public report cards and regulatory oversight. Given that nonprofit and government providers lack a defined shareholder, there may be less incentive for these firms to maximize profits and greater incentive to maximize other objectives such as unobservable quality and the provision of public goods (Newhouse 1970; Hansmann 1980). Thus, conversion to forprofit status is predicted to increase profit-seeking behaviors such as the reduction of hard-to-monitor dimensions of quality, while, the opposite is predicted to occur when nursing homes convert away from for-profit status.

\section{Explanations for Ownership Conversions and Postconversion Behaviors}

Sloan, Ostermann, and Conover (2003) developed a conceptual framework for analyzing hospital conversions and closures. This same framework can also be applied to nursing homes. The basic implication of the model is thatholding other factors constant-poorly run facilities with low profit margins will undergo some type of transaction. Ownership changes are most likely at low or slightly negative margins, while very negative margins are predictive of closure. Similarly, given variation in the cost of capital across owners, highly leveraged facilities are likely to undergo conversions. Finally, for-profit nursing homes are more likely to be involved in transactions, because they are more responsive to market changes (Steinwald and Neuhauser 1970).

Beyond these facility- and market-specific factors, there are also broader factors that may influence nursing home conversions. Over the past three 
decades, both the Medicaid and Medicare programs have changed how they pay nursing homes. An important development has been the increased adoption of Medicaid case-mix payment systems, which pay nursing homes based on resident acuity (Grabowski et al. 2004). There is some evidence that for-profit facilities have strategically sought out states with case-mix adjusted payment (Floyd 2004). On the Medicare side, the adoption of a prospective payment system (PPS) in 1998 altered both the marginal and average reimbursement for providing postacute nursing home services. Given the large forprofit chain presence in the postacute marketplace, this payment change may have increased the number of conversions, at least temporarily. Finally, the recent rise in lawsuits against nursing homes may have led to an increase in conversion in high litigation states (Stevenson and Studdert 2003). In response to higher liability insurance premiums and overall increased practice costs, several publicly traded companies divested their assets and exited from highlitigation states to reduce medical malpractice exposure.

\section{Previous Literature on Conversions in the Health Sector}

We were not able to identify previous research examining the implications of nongovernmental ownership conversions for nursing home performance. In a related study, Holmes (1996) used Michigan cost report data to examine the effect of facility sales on nursing home costs. Importantly, this earlier study included all sales of nursing homes, regardless of whether there was a change in ownership type. The results indicated that nursing homes experiencing a sale over the previous 5 years had higher capital-based costs, but similar patient-related costs. There are large literatures examining hospital and health plan ownership conversions, with some of the studies employing a similar estimation strategy to our own. The results of these hospital and health plan studies were mixed with some finding few changes following ownership conversions (Town, Feldman, and Wholey 2004), others finding transitory changes (Picone, Chou, and Sloan 2002), and still others showing permanent changes along particular dimensions (Shen 2003; Farsi 2004).

\section{DATA}

We utilize two primary sources of nursing home data in this study. The first source of nursing home data is the Online Survey, Certification, and Reporting (OSCAR) system. The OSCAR system contains information from state surveys of all federally certified Medicaid (nursing facilities) and Medicare 
(skilled-nursing care) homes in the United States. Certified homes represent almost 96 percent of all facilities nationwide (Strahan 1997). Collected and maintained by the Centers for Medicare and Medicaid Services (CMS), the OSCAR data include information about whether homes are in compliance with federal regulatory requirements. Every facility is required to have an initial survey to verify compliance. Thereafter, states are required to survey each facility no less often than every 15 months, and the average is about 12 months (Harrington et al. 1999). The OSCAR data include results from survey inspections providing information on nursing home ownership, structure (e.g., number of beds) and staffing level information (by job category), observed deficiencies, and the availability of various services. We have 194,556 OSCAR surveys for the period 1993 through 2004.

Second, we use QI data available from the Minimum Data Set (MDS). The MDS is designed to assess resident functional, cognitive, and affective levels. The MDS has demonstrated good reliability and validity in measuring nursing home quality at the resident level (Morris et al. 1997). Nursing homes have been required to submit these data electronically since June 1998. Facility-level QIs are reported monthly by CMS and provide the number of residents in the numerator and denominator for the QIs. Because all residents are surveyed once per quarter, we aggregated the monthly QI data up to the quarter level. Thus, we have facility-level QI data across 24 quarters (first quarter of 1999 through the final quarter of 2004). Ultimately, we have 383,937 facility-quarter records.

Finally, data on aggregate state Medicaid payment rates and case-mix payment methods were obtained from multiple sources (Harrington et al. 1999; Grabowski et al. 2004).

\section{Ownership Conversions}

At each OSCAR survey, we have information on whether the facility is a forprofit, nonprofit, or government-owned facility. Importantly, an OSCAR survey is required whenever there is a change in facility ownership, providing us with the approximate date of ownership conversion. With this measure, we are able to create a quarterly ownership measure to match with the MDS QIs. Basically, each MDS quarter is assigned the most recent OSCAR ownership value. Importantly, we have OSCAR surveys predating the MDS in order to obtain ownership values for the early quarters of our MDS panel.

Although the organizational characteristics in the OSCAR have shown strong validity (Straker 1999), we were concerned about measurement error 
over time. As such, we checked the ownership field against a text field in the OSCAR containing the name of the chain. If a chain-owned facility converted ownership status, we would expect to see a corresponding change in the chain name text field. There was a very strong correspondence between changes in the ownership field and changes in the chain name field, suggesting that changes in the ownership field identify true changes in ownership and not data errors. We dropped those cases $(<1$ percent) in which we observed a discrepancy between changes in the ownership and chain name fields.

Because government nursing homes are unique in terms of mission, financing, resident needs, and geographic location, we assert that government conversions are better studied under a separate framework (Amirkhanyan 2007). As such, we focus the analyses and discussion on nonprofit and for-profit conversions. However, it is important to note that all the results presented in this study also control for government conversions.

\section{Outcomes}

We estimate models using outcomes from both the OSCAR and MDS data; see Table 1 for descriptive statistics. From the OSCAR, we examine both the facility occupancy rate (residents/beds) and the proportion of Medicaid residents within the facility. We also examine the number of registered nurses (RNs), licensed practical nurses (LPNs), and nurse aides (NAs) per resident day. The staffing data reported on OSCAR are notoriously noisy (Straker 1999) and we have followed earlier work in cleaning these data (Zhang and Grabowski 2004). Finally, we also examine the count of health-related deficiencies assigned via the CMS survey process and whether the facility received a serious (i.e., "G-level or higher") deficiency.

MDS QIs were developed from the MDS as part of the nursing home case mix and quality demonstration. MDS QIs are facility-level indicators for use by state surveyors to monitor changes in residents' health status and care outcomes and to identify potential problem areas at particular facilities. Some of the MDS QIs are stratified by resident characteristics related to risk whereas others are not. MDS QIs have shown good reliability in identifying potential quality problems (Zimmerman et al. 1995; Karon, Sainfort, and Zimmerman 1999). For this study, we have chosen the particular domains validated by CMS and included on the Nursing Home Compare report card initiative available on the Medicare.gov website. These domains include: (1) loss of ability in basic daily activities; (2) infections; (3) pain; (4) pressure sores (high risk); (5) pressure sores (low risk); (6) physical restraints; (7) excessive weight 
Table 1: Sample Means and Standard Deviations

\begin{tabular}{|c|c|c|c|c|}
\hline & \multicolumn{2}{|c|}{$\begin{array}{l}\text { OSCAR Analyses } \\
\text { (1993-2004) }\end{array}$} & \multicolumn{2}{|c|}{$\begin{array}{c}\text { Quality Indicator } \\
\text { Analyses (1999-2004) }\end{array}$} \\
\hline & Mean & $S D$ & Mean & $S D$ \\
\hline \multicolumn{5}{|l|}{ Dependent variables } \\
\hline Occupancy (\%) & 0.83 & 0.20 & & \\
\hline Percent Medicaid & 0.62 & 0.27 & & \\
\hline $\mathrm{RN}$ hours per resident day & 0.51 & 0.79 & & \\
\hline LPN hours per resident day & 0.76 & 0.68 & & \\
\hline NA hours per resident day & 2.05 & 0.83 & & \\
\hline Health-related deficiencies & 6.13 & 6.48 & & \\
\hline G-level (or higher) deficiency & 0.19 & 0.39 & & \\
\hline Depression & & & 0.13 & 0.13 \\
\hline Incontinence & & & 0.58 & 0.16 \\
\hline Catheter & & & 0.081 & 0.102 \\
\hline Urinary tract infection & & & 0.089 & 0.082 \\
\hline Weight loss & & & 0.12 & 0.10 \\
\hline Bedfast & & & 0.069 & 0.110 \\
\hline Activity of daily living decline & & & 0.17 & 0.11 \\
\hline Range of motion decline & & & 0.083 & 0.082 \\
\hline Physical restraint & & & 0.093 & 0.101 \\
\hline Pressure ulcer, high risk & & & 0.16 & 0.12 \\
\hline Pressure ulcer, low risk & & & 0.036 & 0.073 \\
\hline \multicolumn{5}{|l|}{ Control variables } \\
\hline Government & 0.063 & 0.243 & 0.061 & 0.239 \\
\hline Chain-owned & 0.53 & 0.50 & 0.54 & 0.50 \\
\hline Hospital-based & 0.12 & 0.32 & 0.084 & 0.28 \\
\hline Activities of daily living $(0-5)$ & 3.78 & 0.61 & 3.81 & 0.59 \\
\hline Beds, 0-49 & 0.15 & 0.36 & 0.12 & 0.36 \\
\hline Beds, 50-99 & 0.35 & 0.48 & 0.36 & 0.48 \\
\hline Beds, 100-149 & 0.31 & 0.46 & 0.33 & 0.46 \\
\hline Beds, 150-199 & 0.11 & 0.31 & 0.12 & 0.31 \\
\hline Beds, 200+ & 0.077 & 0.267 & 0.078 & 0.268 \\
\hline Herfindahl index & 0.22 & 0.23 & 0.22 & 0.23 \\
\hline Medicaid payment rate $(\$ 2004)$ & 110.88 & 26.22 & 120.69 & 25.22 \\
\hline Medicaid case-mix payment & 0.58 & 0.49 & 0.66 & 0.47 \\
\hline Number of observations & 194,556 & & 383,937 & \\
\hline
\end{tabular}

Notes: The 1993-2004 Online Survey, Certification and Reporting (OSCAR) system consists of roughly one observation per year. The quality indicators are observed quarterly beginning in the first quarter of 1999 through the final quarter of 2004.

$\mathrm{RN}$, registered nurse; LPN, licensed practical nurse; NA, nurse aide.

loss; (8) spent most of their time in bed or in a chair; (9) ability to move about in and around their room got worse; (10) have become more depressed or anxious; (11) lose control of their bowels or bladder (low risk); and (12) have/had a catheter inserted and left in their bladder. 


\section{EMPIRICAL FRAMEWORK}

We estimate the following model:

$$
\begin{aligned}
Y_{i t}= & \sum_{-\mathrm{k}<j<m} \varphi_{j} \mathrm{NFP} \text { to } \mathrm{FP}_{i t}^{j}+\sum_{-\mathrm{k}<j<m} \theta_{j} \mathrm{FP} \text { to } \mathrm{NFP}_{i t}^{j}+\gamma \mathrm{X}_{i t} \\
& +\eta_{\mathrm{s}}+\lambda_{\mathrm{t}}+\varepsilon_{i t}
\end{aligned}
$$

where $Y$ is the outcome variable of interest in nursing home $i$ at time $t, X$ is a set of time-varying characteristics, $\eta_{\mathrm{s}}$ and $\lambda_{\mathrm{t}}$ are nursing home and time-fixed effects and $\varepsilon_{i t}$ is the error term. The key variables of interest are the set of indicators ( $\mathrm{NFP}$ to $\mathrm{FP}^{j}$ and $\mathrm{FP}$ to $\mathrm{NFP}^{j}$ ) measuring the periods leading up to an ownership conversion, the period of conversion, and the periods following conversion. Nursing homes experiencing a decline in quality may be more likely to experience a conversion. If performance is found to be substandard after the conversion, this may be attributable to the reduced quality that preceded the conversion rather than the conversion itself. Thus, the preconversion terms (the $-\mathrm{k}$ terms) allow for a changing pattern of quality in the periods before conversion. That is, this model allows for any deterioration in outcomes that is not conversion related, but is correlated with conversion. Then, we include terms for the periods after conversion (the $\mathrm{m}$ terms) to measure how outcomes evolve once the facility changes ownership type. For the OSCAR outcomes, the excluded reference category is $6+$ years before the conversion. For the MDS outcomes, the excluded category is $4+$ years before conversion.

In this model, the nursing home fixed effects control for any fixed facility-specific omitted variables correlated with the quality of care such as the facility's management philosophy or facility culture. Thus, the basic identification strategy implicit in Equation (1) purges the unobserved and potentially confounded cross-sectional heterogeneity by relying on the withinfacility variation across ownership over time and by using homes that did not experience changes in ownership as a control for unrelated time-series variation.

The vector of control variables, $X$, includes a set of time varying, facilitylevel variables obtained from the OSCAR including bed size dummies, government status, chain membership status, hospital-based status, and a facility-level activities of daily living (ADL) score. A potential concern is that the ADL score may be endogenous to facility-level quality. However, our results are robust to excluding this measure from the model. At the marketlevel, we formulate a Herfindahl-Hirschman index (HHI) measure using 
facility beds as the measure of nursing home size. For each facility in our sample, we define a nursing home market to be the $25 \mathrm{~km}$ circle about the facility. Finally, we also control for the state-level Medicaid payment rate and the presence of case-mix-adjusted Medicaid payment.

We estimate the staffing models using least squares, the count of deficiencies measure using a negative binomial model and the G-level deficiency measure using a logit model. Because the occupancy, Medicaid and QIs are represented as a percentage of residents, we use the logit transformation so dependent variables are of the form $\ln \left(\frac{P_{i}}{1-P_{i}}\right)$ where $P_{i}$ represents the proportion of residents of nursing home $i$. Because the logit transformation assigns no value when the percent is equal to either 0 or 1,0 values were recoded as 0.0001 and values of one were recoded as 0.9999 . In each regression, observations are weighted according to the number of residents in nursing home $i$ at time $t$. Because we have multiple observations on each facility, standard errors are clustered at the level of the nursing home.

\section{RESULTS}

\section{Annual Trend in Conversions}

There were 1,151 conversions from for-profit to nonprofit status and 1,019 from nonprofit to for-profit status (see Table 2). As a benchmark, there are approximately 16,000 unique nursing homes in the United States at any given time. The annual rate of nursing home conversions almost tripled between 1994 and 2004. Although we focus the discussion below on nonprofit and forprofit conversions, there were also conversions involving government facilities over our period of study. Specifically, there were 108 for-profit to government conversions, 153 government to for-profit conversions, 219 nonprofit to government conversions, and 251 nonprofit to government conversions.

\section{Regression Results}

If we observed random variation in provider behavior in the years before conversion followed by large, statistically significant coefficient estimates for the transition and posttransition terms, then this may suggest a causal effect of conversions on quality. In general, however, the results are not suggestive of such a relationship (see Table 3). Although all the pretransition terms are not statistically significant, they are large in magnitude and suggest that quality trends generally began before ownership conversion. Specifically, facilities converting from for-profit to nonprofit typically exhibited improvement in the preconversion 


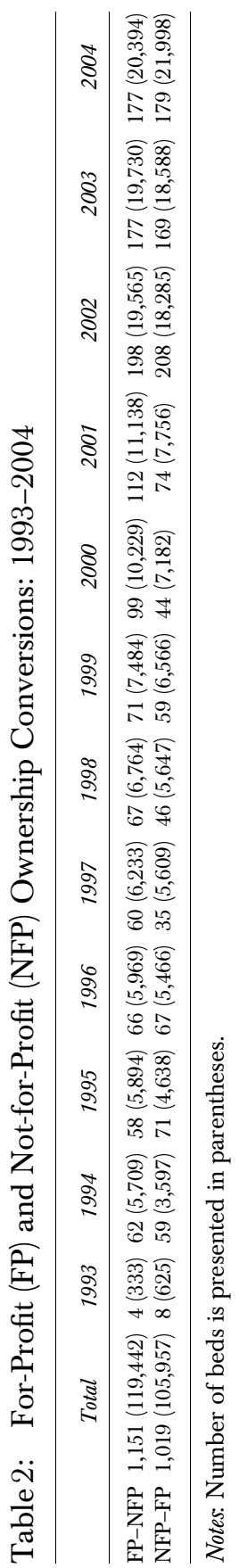



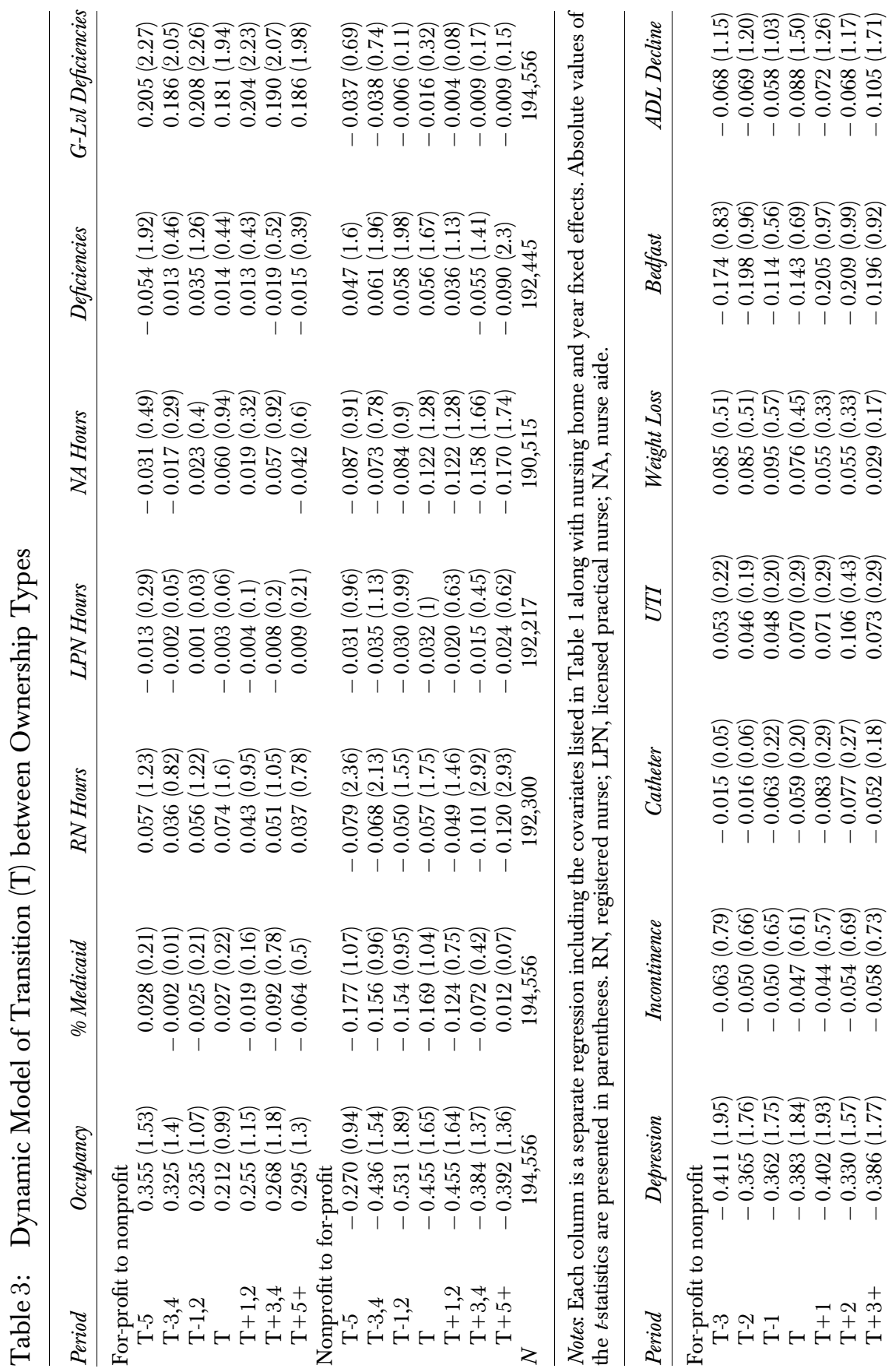

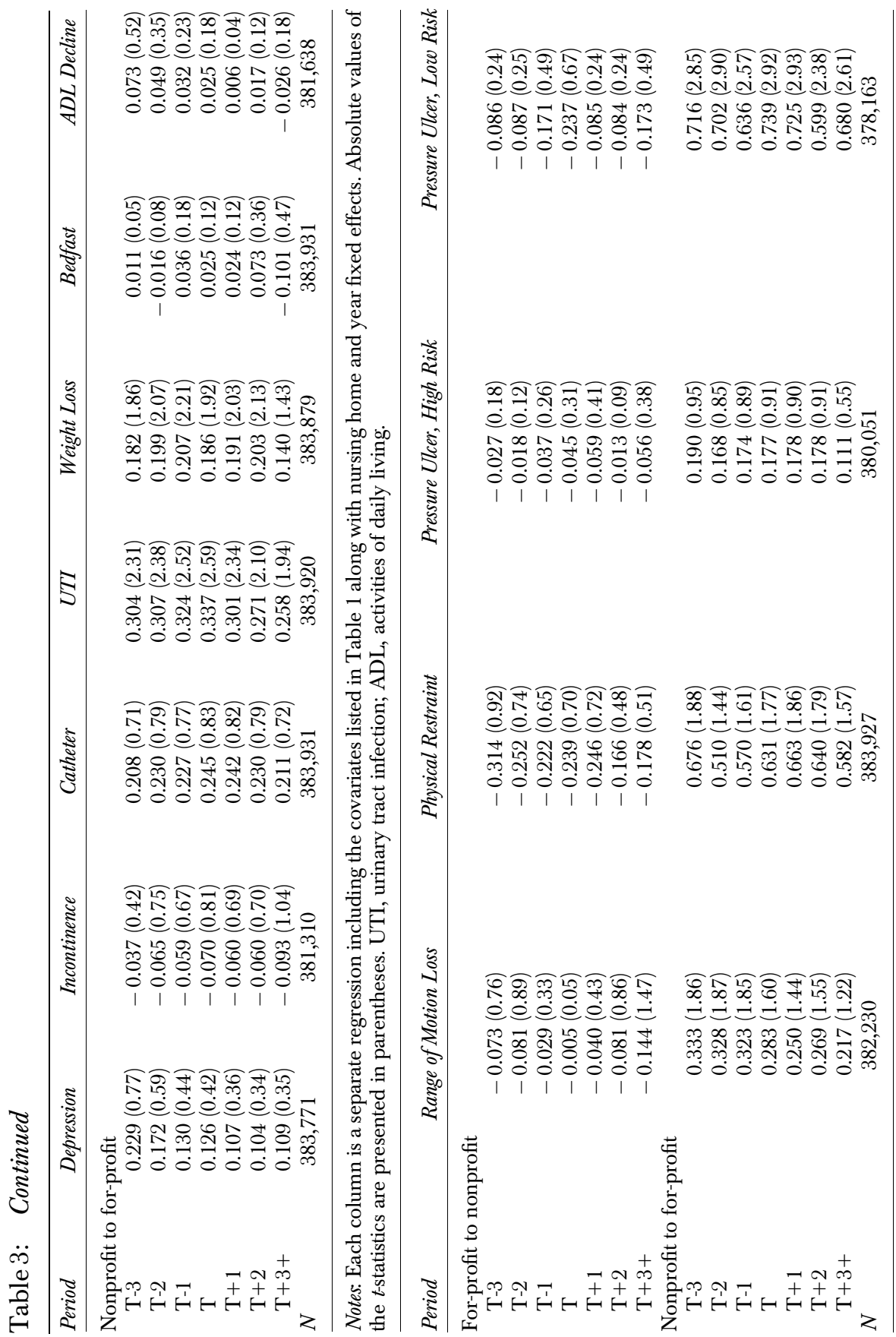
period such as increasing occupancy rates and RN staffing. This improvement in performance persists to the periods following conversion. Similarly, facilities converting from nonprofit to for-profit status can be characterized by declining performance with lower occupancy; fewer RN, LPN, and NA hours; and higher deficiencies in both the pre and postconversion periods.

Of the 12 MDS-based outcomes, nine indicate facilities converting from forprofit to nonprofit status exhibit improvement in both the pre and postconversion periods. Specifically, the depression, incontinence, catheter, bedfast, ADL decline, range of motion loss, and both pressure ulcer measures suggest that quality is consistently declining for these facilities. Similarly, the depression, catheter, urinary tract infection, weight loss, range of motion loss, physical restraint, and both pressure ulcer measures indicate that facilities converting to for-profit status are consistently improving performers across the preand postconversion periods.

The difference in facilities converting across ownership types is shown graphically in Figure 1 for four outcomes: occupancy rate, RN staffing, catheter use, and pressure ulcers (high risk). In this figure, the estimated coefficients from Table 3 have been transformed to a percentage of the dependent variable mean. There is a distinct trend in the performance of facilities acquired by for-profits and nonprofits, and this trend persists in the postconversion period, suggesting little causal effect of ownership conversions on nursing home performance.

\section{Alternate Model Specifications}

In an effort to evaluate the robustness of our results, we estimated a series of alternate models. First, we used propensity score weighting to construct matching control groups for converting facilities over our period of study. We then reestimated the models presented in Table 3, but including only converting facilities and these control facilities. This alternate model produced very similar results in terms of magnitude and precision to those presented in Table 3 (these results are available upon request from the authors). Second, a potential concern with the inclusion of facility-fixed effects is that these terms limit the degree of precision in the model. As a check, we re-estimated the model using state-fixed effects. This model produced qualitatively similar estimates, but as expected, the standard errors were generally smaller.

Finally, we were also interested in determining whether the sales of facilities within ownership categories exhibited similar trends to those observed for ownership conversions. Unfortunately, there is not currently a national repository of nursing home sales for our period of study. However, 
Figure 1: Pre/Postconversion Trends.
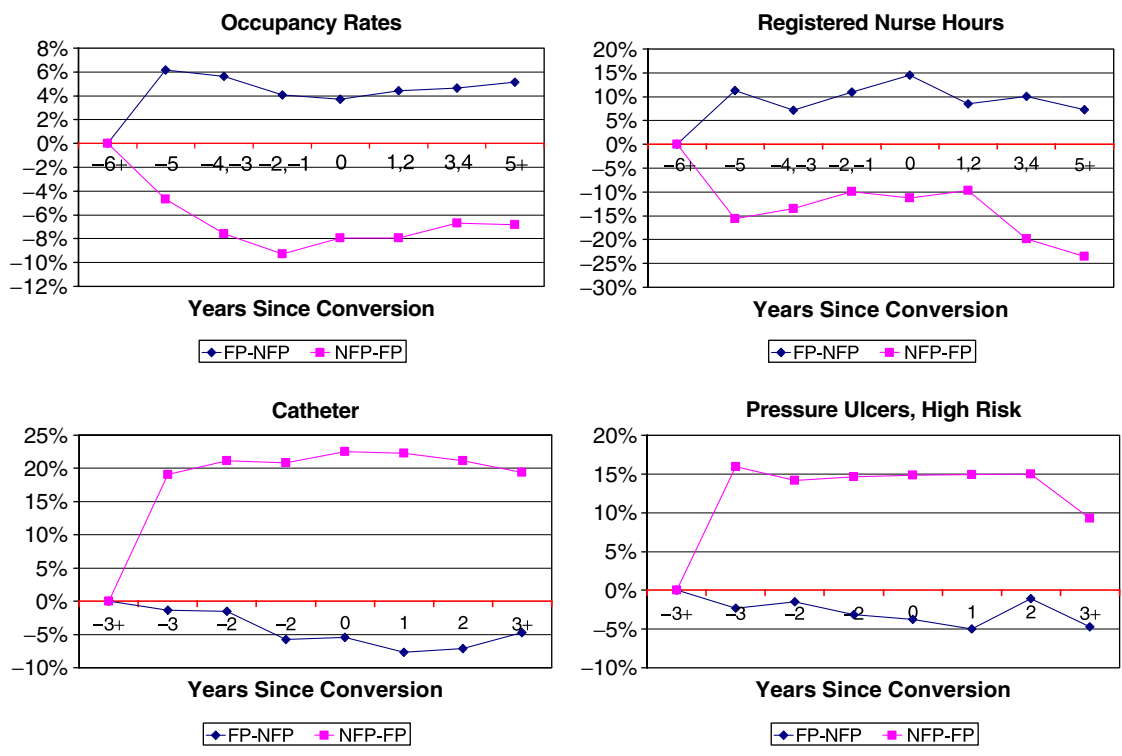

Notes: Coefficient estimates from Table 3 have been converted to a percentage of the dependent variable mean.

using identifiers for the major for-profit chains, we were able to track acquisitions and divestitures of facilities by these chains. In total, there were 7,468 such sales over the entire period of study. Using the same methods employed in Table 3, facilities undergoing a for-profit to for-profit sale had more Medicaid residents, greater deficiencies, and worse performance on QIs in the periods before conversion. Taken together with our primary findings, these results suggest that for-profit facilities acquired by nonprofits are typically exhibiting an improvement in performance, while facilities acquired by for-profits are typically exhibiting a decline in performance.

\section{DISCUSSION}

We found little evidence to suggest a causal relationship between ownership conversions and nursing home performance. However, we did find evidence suggesting that converting nonprofit and for-profit facilities differ from their nonconverting counterparts. That is, facilities converting from nonprofit to 
for-profit status are generally declining performers, while facilities converting from for-profit to nonprofit facilities are generally improving performers. This finding gives rise to two important questions. First, why do for-profit nursing homes acquire declining nursing homes and sell off improving nursing homes? And second, why does facility quality generally not change postconversion?

Toward the first question, in the context of incomplete information on the part of nursing home consumers (Chou 2002), it is not clear that the provision of better quality care necessarily translates into higher profits. There is some research suggesting that poor quality facilities are more likely to close (Angelelli et al. 2003), but these closures are relatively infrequent, and consistently poor nursing homes continue to operate in many markets (Grabowski and Castle 2004). Indeed, very few nursing home consumers have been found to use either exit (Hirth, Banaszak-Holl, and McCarthy 2000) or voice (Stevenson 2005) in response to poor nursing home quality. If there is not a direct return to providing higher quality, it may be the case that forprofits are willing to divest of improving nursing homes and acquire declining nursing homes. Conversely, because nonprofit providers lack a defined shareholder, there may be a greater incentive to maximize objectives other than profit such as the difficult-to-monitor dimensions of quality.

The answer to the second question - why does quality generally not change postconversion?-likely relates to the fact that for-profits and nonprofits tend to acquire and divest of facilities in ways that are consistent with their objectives. For example, if nonprofits acquire improving nursing homes, we would not necessarily expect a further change in the quality of care. Although one might expect some "regression to the mean" in terms of nursing home quality following a conversion, other research has shown some persistence in quality over time (Grabowski and Castle 2004). Given that the frontline staff reportedly do not typically change after a conversion, it is perhaps not surprising that many indicators of facility quality remain relatively constant following a conversion. There is some support for this finding from the hospital literature. Using California data, Ferris and Graddy (1999) found that for-profit hospitals converting to nonprofit status provided more charity care before conversion than the average for-profit hospital. Likewise, nonprofit hospitals that converted to for-profit status provided less charity care than the average nonprofit hospital.

Given that this is one of the first studies to analyze nursing home ownership conversions, there are several potential extensions to explore in future work. First, it will be important to replicate these analyses with a measure of costs or profit margins as the outcome of interest. Once again, it 
may be the case that for-profits are selling off less profitable, but higher quality, facilities, to acquire more profitable, but lower quality, facilities. There also may be important geographic dimensions to nursing home conversions in the context of varying litigation climates and payment policies across states. As such, it may be fruitful to conduct in-depth analyses of high/low litigation or payment states. Finally, recent work has established that market ownership share matters toward the provision of quality, with an increase in nonprofit market share improving quality among for-profit nursing homes (Grabowski and Hirth 2003). Thus, in a potential linkage of these two lines of research, one could analyze whether market share matters toward explaining quality of care following a conversion.

It may also be useful to apply a similar analytic framework to withinownership transactions in the nursing home sector. Although analyzing conversions is particularly useful to assess the impact of ownership type, the majority of facility transactions occur between companies with common ownership type. As mentioned above, for example, the largest national chains have undergone considerable restructuring over the last decade, most recently with the involvement of private equity firms and, more broadly, the separation of real estate and other assets from care operations (Stevenson, Grabowski, and Coots 2006; Duhigg 2007a). There is some existing research analyzing the role of chain ownership and quality of care during the early and mid-1990s (Banaszak-Holl et al. 2002), but it is important to update these analyses in the context of the changing corporate structures, the rise of litigation, Medicaid payment changes, and the adoption of Medicare PPS in recent years.

In sum, the previous literature on nursing home ownership has typically argued that nonprofits provide higher quality relative to for-profit facilities. However, the results of this paper are not consistent with a causal relationship between ownership conversions and quality. Facilities converting from nonprofit to for-profit status tend to be of higher quality, while facilities converting in the other direction tend to be of lower quality. These results imply that regulators and policy makers should not only monitor the outcomes of nursing home conversions, but also the targets of these conversions.

\section{ACKNOWLEDGMENTS}

Joint Acknowledgment/Disclosure Statement: This research was supported by the J.W. Kieckhefer Foundation and data were analyzed under Centers for Medicare and Medicaid Services data use agreement no. 18023. We are 
grateful to Tom McGuire and seminar participants at Harvard University, the International Health Economics Association, RAND, the Triangle Health Economics Workshop, University of Connecticut, and University of Montreal for comments.

\section{REFERENCES}

Amirkhanyan, A. A. 2007. "The Smart-Seller Challenge: The Determinants of Privatizing Public Nursing Homes.” Journal of Public Administration Research and Theory 17 (3): 501-27.

Angelelli, J., V. Mor, O. Intrator, Z. Feng, and J. Zinn. 2003. "Oversight of Nursing Homes: Pruning the Tree or Just Spotting Bad Apples?" Gerontologist 43 (spec. no. 2): 67-75.

Banaszak-Holl, J., W. B. Berta, D. M. Bowman, J. A. C. Baum, and W. Mitchell. 2002. "The Rise of Human Service Chains: Antecedents to Acquisitions and Their Effects on the Quality of Care in US Nursing Homes.” Managerial and Decision Economics 23 (4-5): 261-82.

Chou, S. Y. 2002. "Asymmetric Information, Ownership and Quality of Care: An Empirical Analysis of Nursing Homes." Journal of Health Economics 21 (2): 293-311.

Duhigg, C. 2007a. “At Many Homes, More Profit and Less Nursing." New York Times. pp. A-1.

—. 2007b. "Inquiries at Investor-Owned Nursing Homes." New York Times. pp. C1.

Farsi, M. 2004. "Changes in Hospital Quality after Conversion in Ownership Status." International Journal of Health Care Finance and Economics 4 (3): 211-30.

Ferris, J. M., and E. A. Graddy. 1999. "Structural Changes in the Hospital Industry, Charity Care and the Nonprofit Role in Health Care." Nonprofit and Voluntary Sector Quarterly 28 (1): 18-31.

Floyd, W. R. 2004. "Beverly Enterprises Investor Update.” CIBC World Markets Healthcare Conference. November 9, New York.

Grabowski, D. C., and N. G. Castle. 2004. "Nursing Homes with Persistent High and Low Quality." Medical Care Research and Review 61 (1): 89-115.

Grabowski, D. C., Z. Feng, O. Intrator, and V. Mor. 2004. "Recent Trends in State Nursing Home Payment Policies." Health Affairs (suppl, Web Exclusives): W4: 363-73.

Grabowski, D. C., and R. A. Hirth. 2003. "Competitive Spillovers across Non-Profit and for-Profit Nursing Homes." Journal of Health Economics 22 (1): 1-22.

Hansmann, H. B. 1980. “The Role of Nonprofit Enterprise.” Yale Law Journal 89 (5): 835-901.

Harrington, C., J. H. Swan, V. Wellin, W. Clemena, B. Bedney, and H. Carillo. 1999. 1998 State Data Book on Long Term Care Program and Market Characteristics. San Francisco: Department of Social and Behavioral Sciences, University of California. 
Hillmer, M. P., W. P. Wodchis, S. S. Gill, G. M. Anderson, and P. A. Rochon. 2005. "Nursing Home Profit Status and Quality of Care: Is There Any Evidence of an Association?" Medical Care Research and Review 62 (2): 139-66.

Hirth, R. A., J. C. Banaszak-Holl, and J. F. McCarthy. 2000. "Nursing Home-toNursing Home Transfers: Prevalence, Time Pattern, and Resident Correlates.” Medical Care 38 (6): 660-9.

Holmes, J. S. 1996. "The Effects of Ownership and Ownership Change on Nursing Home Industry Costs." Health Services Research 31 (3): 327-46.

Institute of Medicine. 2001. Improving the Quality of Long-Term Care. Washington, DC: National Academy Press.

Karon, S. L., F. Sainfort, and D. R. Zimmerman. 1999. "Stability of Nursing Home Quality Indicators over Time.” Medical Care 37 (6): 570-9.

Morris, J. N., S. Nonemaker, K. Murphy, C. Hawes, B. E. Fries, V. Mor, and C. Phillips. 1997. "A Commitment to Change: Revision of HCFA's RAI." Journal of the American Geriatrics Society 45 (8): 1011-6.

National Center for Health Statistics. 2006. "2004 Facility Tables” [accessed on December 26, 2006]. Available at http://www.cdc.gov/nchs/data/nnhsd/ nursinghomefacilities2006.pdf\#01

Newhouse, J. P. 1970. "Toward a Theory of Nonprofit Institutions: An Economic Model of a Hospital." American Economic Review 60 (1): 64-74.

Norton, E. C., and D. O. Staiger. 1994. "How Hospital Ownership Affects Access to Care of the Uninsured." Rand Journal of Economics 25 (1): 171-85.

Picone, G., S. Y. Chou, and F. Sloan. 2002. "Are For-Profit Hospital Conversions Harmful to Patients and to Medicare?" Rand Journal of Economics 33 (3): $507-23$.

Shen, Y. C. 2003. "Changes in Hospital Performance after Ownership Conversions." Inquiry 40 (3): 217-34.

Sloan, F. A., J. Ostermann, and C. J. Conover. 2003. "Antecedents of Hospital Ownership Conversions, Mergers, and Closures." Inquiry 40 (1): 39-56.

Smith, C., C. Cowan, S. Heffler, and A. Catlin. 2006. "National Health Spending in 2004: Recent Slowdown led by Prescription Drug Spending." Health Affairs (Millwood) 25 (1): 186-96.

Spillman, B. C., and J. Lubitz. 2002. "New Estimates of Lifetime Nursing Home Use: Have Patterns of Use Changed?" Medical Care 40 (10): 965-75.

Steinwald, B., and D. Neuhauser. 1970. "The Role of the Proprietary Hospital." Law and Contemporary Problems 35: 817-38.

Stevenson, D. G. 2005. "Nursing Home Consumer Complaints and Their Potential Role in Assessing Quality of Care." Medical Care 43 (2): 102-11.

Stevenson, D., D. Grabowski, and L. Coots. 2006. "Nursing Home Divestiture and Corporate Restructuring: Final Report.” Prepared for Office of Disability, Aging and Long-Term Care Policy, Office of the Assistant Secretary for Planning and Evaluation, U.S. Department of Health and Human Services, Contract \#HHS100-03-0033. 
Stevenson, D. G., and D. M. Studdert. 2003. "The Rise of Nursing Home Litigation: Findings from a National Survey of Attorneys." Health Affairs (Millwood) 22 (2): 219-29.

Strahan, G. W. 1997. An Overview of Nursing Homes and Their Current Residents: Data from the 1995 National Nursing Home Survey. Rockville, MD: National Center for Health Statistics, Centers for Disease Control and Prevention, U.S. Department of Health and Human Services.

Straker, J. K. 1999. Reliability of OSCAR Occupancy, Census and Staff Data: A Comparison with the Ohio Department of Health Annual Survey of Long-Term Care Facilities. Technical Report 3-01. Oxford, OH: Scripps Gerontology Center.

Town, R., R. Feldman, and D. Wholey. 2004. "The Impact of Ownership Conversions on HMO Performance." International Journal of Health Care Finance and Economics 4 (4): 327-42.

Zhang, X., and D. C. Grabowski. 2004. "Nursing Home Staffing and Quality under the Nursing Home Reform Act." Gerontologist 44 (1): 13-23.

Zimmerman, D. R., S. L. Karon, G. Arling, B. R. Clark, T. Collins, R. Ross, and F. Sainfort. 1995. "Development and Testing of Nursing Home Quality Indicators." Health Care Financing Review 16 (4): 107-27.

\section{SUPPLEMENTARY MATERIAL}

The following supplementary material for this article is available online:

Appendix SA1: HSR Author Matrix.

This material is available as part of the online article from http:// www.blackwell-synergy.com/doi/abs/10.1111/j.1475-6773.2008.00841.x (this link will take you to the article abstract).

Please note: Blackwell Publishing is not responsible for the content or functionality of any supplementary materials supplied by the authors. Any queries (other than missing material) should be directed to the corresponding author for the article. 